\section{DISTRIBUIÇAOO GEOGRÁFICA E FREQÜÊNCIA DA GASTEROFILOSE EM EQUIDEOS ABATIDOS EM ARAGUARI, MINAS GERAIS}

\section{MARIA JOSE SANTOS MUNDIM \\ Professor Assistente}

Universidade Federal de Uberlândia

DAGMAR DINIZ CABRAL

Professor Adjunto

Universidade Federal de Uberlândia

VALMIR TUNALA

Médico Veterinário

Ministério da Agricultura, MG

MUNDIM, M.J.S.; CABRAL, D.D.; TUNALA, V. Distribuiçăo geografica e freqülncia da gasterofilose em eqüideos abatidos em Araguari, Minas Gerais. Braz. J. vet Res. anim. Scl., Sảo Paulo, v.29, n.2, p.211-3, 1992.

RESUMO: Em um estudo feito no Frigorífico FAVA S/A Avaguari, Minas Gerais, verificou-se que de 14.162 eqüídeos abatidos, procedentes de 9 estados brasileiros, no período compreendido entre 14 de maio de 1987 a 10 de maio de $1988,31,49 \%$ achavam-se positivos para larvas de moscas do gênero Gasterophilus. Durante este período foram encontrados animais positivos procedentes de 7 estados: Mato Grosso do Sul $(85,71 \%)$; Săo Paulo $(75,95 \%)$; Parań́ (65,61\%); Goiás (44,02\%); Mato Grosso (42,03\%); Minas Gerais $(14,03 \%)$ e Pará $(8,33 \%)$, enquanto animas negativos procederam de 2 estados: Espirito Santo e Rio de Janeiro. Foram estudados 226 municípios nesses estados e $7,43 \%$ desses apresentaram eqüídeos positivos para gasterofilose. A especie identificada foi a G. nasalis.

UNITERMOS: Gasterofiliase; Epidemiologia; Eqüinos

\section{INTRODUÇAO}

A família Gasterophilidae, que zo caracteriza por albergar muscóides com 8 - $18 \mathrm{~mm}$ de comprimento, com abundantes cerdas na cabeça, no tórax e no abdome. olhos facetados desnudos e elementos bucais muito reduzidos, $\theta$ dividida em quatro subfamílias, sendo que apenas a Gasterophilinae ocorre no Novo Mundo (GUIMARÃES et al. 5 1983; BOCH: SUPPERER 1, 1986). Sảo conhecidas nove espécies do gênero Gasterophilus parasitando o tubo digestivo de eqüídeos: G. intestinalis; $G$. nasalis; $G$. haemorrhoidalis; G. inermis; G. pecorum; G. nigricornis; G. lativentris; G. ternicinctus o G. meridionalis, sendo G. intestinalls e G. nasalis as espécies mais comuns na Europa Central e no Brasil (ZUMPT ${ }^{12}, 1965$ ).

Na região neotropical ocorrem três espécies do gênero Gasterophilus: G. intestinalis, G. haemorhoidalis $\theta$ G. nasalis, sendo esta última a mais freqüente (GUIMARAES of a). 5,1983 ). Segundo (IHERING 7,1930 ; ROCHA ${ }^{10}, 1954$ ), G. nasalis 6 a única espécie cuja adaptação no Brasil está bem documentada.

A ocorrencia de G. intestinalis em eqüinos importados da França foi relatada por (GUIMARẢES ot al. 6 , 1954).

No Rio Grande do Sul, (OLNEIRA et al. 8 , 1972) encontraram uma incidência de $86,40 \%$ em 1000 animais examinados, sendo G. nasalls a única espócie assinalada

EDWARDS 2, 1982 extudou a prevalencia da G. intestinalis om 448 cavalos procedentes do norte da Inglaterra, encontrando $52,70 \%$ de positividade.

PANDEY ot al. 9,1980 examinando 94 eqüinos em Marrocos, encontraram 100,00\% infestados por G. Inteatinalis $\theta 89$ destes animais por G. naealls.

Os danos causados aos animais pela presença da larva deste díptero 6 proporcional ao grau de infestaçăo, podendo haver desde dificuldade para a passagem de alimento, devido à obstruçāo do piloro, até a ruptura do estómago, causando-lhes danos em graus variáveis $(\mathrm{BOCH}$; SUPPERER ${ }^{1}$, 1986).

É sabido que Gasterophilus ocorre em várias regiōes do Brasil, existindo escassez de dados referentes à sua distribuição geográfica, e concentrando-se na biologia $\theta$ terapoutica das larvas.

Frente à importancia desta doença, o objetivo do presente estudo foi conhecer a distribuiç̧o geográfica da gasterofilose em eqüídeos abatidos em Araguari, MG, e a freqüência desta parasitose nos estados e municípios de origem destes animais, durante o período de um ano.

\section{MATERLAL E MÉTODO}

Os dados utilizados para o cáculo da freqüência de gasterofilose foram codidos pelo Frigorífico FAVA S/A Industrial e Comercial (S.I.F. 1803), localizado no municipio de Araguari, Minas Gerais. Foram obtidos entre 14 de maio de 1987 a 10 de majo de 1988, no periodo em que foram abatidos 14.162 animais. Neste levantamento anotaram-se as procederncias dos animais por estado e município pertencentes a diversas zonas fisiográficas.

De cada animal abatido examinou-se o estómago e o duodeno para pesquisa de larvas.

\section{JERVIÇO DE BIBLIOTECA E DOCUMENTAÇAO \\ FACULDADE DE MEDICINA VETERINARIA E ZOOTECNIA DA USSP}




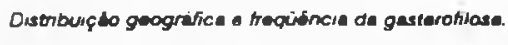

A identificaçăo específica das larvas foi baseada no tamanho, morfologia dos espiráculos respiratórios e caracteristicas dos espinhos segundo WELLS et al. 11 (1938): GUIMARÃES et al. ${ }^{5}$ (1983).

Saliente-se que nảo toi possivel identificar as diferentes especies de equideos, pois o Frigorífico FAVA S/A não fornece esses dados.

\section{RESULTADOS E DISCUSSÃO}

Verificou-se que os animais abatidos no Frigorífico FAVA S/A, município de Araguari, MG, durante o periodo de maio de 1987 a maio de 1988, eram procedentes de 9 estados brasileiros: Mato Grosso do Sul, Săo Paulo, Paraná, Goiás, Mato Grosso, Minas Gerais, Pará, Espirito Santo e Rio de Janeiro. Destes estados, somente os dois últimos apresentaram animais negativos para gasterofilose.

A Tab. 1 evidencia a frequiencia de animais positivos por estados. O total de equídeos foi de 14.162 , sendo que 4.460 (31.49\%) apresentaram larvas de Gasterophilus nasalls. Observou-se que os eqüideos de três estados apresentaram as freqüencias mais elevadas: Mato Grosso do Sul $(85.71 \%)$, Sảo Paulo (75.95\%) e Paraná $(65,61 \%)$, Minas Gerais e Pará foram os de freqüências mais baixas: $14.03 \%$ e 8,33\%, respectivamente. Do Rio de Janeiro e do Espirito Santo provieram 220 animais para 0 abate, mas nenhum com gasterofilose.

GUIMARÃES et al. ${ }^{5}$ (1983) e FREITAS et al. ${ }^{3}$ (1984) relataram, em trabalhos, a presença de larvas destas moscas em vários estados brasileiros, dado este confirmado pelos resultados deste trabalho.

O número de animais abatidos por estado variou consideravelmente, influenciando na freqü̈ncia dos positivos. Vários fatores podem estar interferindo nesta variaçăo, incluindo a distancia entre os municípios ou estado de procedência e o frigorífico, bem como fatores climáticos dessas regióes.

Nos 7 estados onde foram assinalados animais positivos, 226 municipios foram estudados. Desses, 175 municipios enviaram animais positivos $(77,43 \%)$.

OLVEIRA et al. ${ }^{8}$ (1972) encontraram uma infestaçăo de $86.40 \%$ no Rio Grande do Sul, em 1000 equiiros abatidos, procedentes de quarenta e quatro municipios daquele estado. A freqü̈ncia do presente estudo foi baixa, comparando-se com os dados do referido autor para somente este estado, ressaltando-se, ainda, que esta diferença talvez esteja relacionada com fatores fisiográficos de cada regiảo.

Neste estudo observou-se que, a partir da década de 70, poucas pesquisas têm sido feitas com relaçăa a esta parasitose no pais. $O$ presente relato ressalta somente a distribuiçăo geográfica da mosca nos estados e municípios brasileiros, havendo necessidade de estudos mais detalhados sobre a sua açăo no hospedeiro e relaçăo custobenefício.

Todas as larvas foram encontradas na porçăo final do estómago. No presente estudo nảo se encontrou nenhum exemplar no duodeno, resultado este não coincidente com os autores que relatam a localizaçăo preferencialmente no duodeno (ROCHA ${ }^{10}, 1954$; OLIVEIRA et al. ${ }^{8}, 1972$; GUIMARÃES et al. ${ }^{5}, 1983$ ). As lanvas mediram de $11,0-17,0 \mathrm{~mm}$ de comprimento $(\bar{x}=14,2 \mathrm{~mm}$ ), e apresentavam espinhos dispostos numa única fileıra es espiráculos respiratórios com fendas encurvadas na parte média, situadas em uma concavidade rasa segundo GEORGI 4 (1982). Considerando essas caracteristicas, identificamos como sendo G. nasalls.

\section{CONCLUSÓES}

Ao final deste levantamento foi possivel concluir que:

- durante o período de um ano, a freqüência de gasterofilose em 14.162 animais nos estados estudados foi de $31.49 \%$;

- os 7 estados brasileiros que apresentaram animais positivos para larvas de Gasterophilus foram: Mato Grosso do Sul (85,71\%); Sảo Paulo (75,95\%); Paraná (65,61\%); Goiás (44,02\%); Mato Grosso (42,03\%); Minas Gerais $(14,03 \%)$ e Pará $(8,33 \%)$;

- as larvas identificadas foram de G. nasalis.

MUNDIM, M.J.S.; CABRAL, D.D.; TUNALA, V. Geographic distribution and frequency of gasterophilosis in slaughtered horses of Araguari, Minas Gerais. Braz. J. vet Res. anim. Scl., Såo Paulo, v.29, n.2, p.211-3, 1992.

SUMMARY: Fourteen thousand, one Hundred sixthy two slaughtered horses from nine Brazilian states at the FAVA S/A slaughter-house, Araguari, MG; between May, $14^{\text {th }} / 1987$ to May, $10^{\text {th }} / 1988$ and $31.49 \%$ had been Gasterophilus positive. During this period were observed positive animals from 7 different states: Mato Grosso do Sul (85.71\%); Săo Paulo (75.95\%); Paraná (65.61\%); Goiás (44.02\%); Mato Grosso (42.03\%); Minas Gerais (14.03\%); Pará (8.33\%) and negative animals from 2 other states: Espírito Santo and Rio de Janeiro. Animals from 226 cities had been studied and $77.43 \%$ were gasterophilosis positive. The identified species was Gasterophilus nasalis.

UNITERMS: Gasterophilus; Epidemiology; Horse 
01-8OCH, J.: SUPPERER, R. Parashologia em modicina veterinária. Buenos Aires, Hemisferio Sur, 1986.

02-EDWARDS. G.T. The prevalence of Gasterophilus intestinalis in horses in northern England and Wales. Vot Parashol, v.11, p.215-22, 1982.

Q3-FREITAS, M.G.; COSTA, H.M.A.; COSTA, J.O. Manual de entomologia mbdica e vetorinária. 3.ed. Belo Horizonte, Precisa Ed. Gráfica, 1984.

O4GEORGI, J.R. Parastologla veterinarla. Rio de Janeiro, interamericana, 1982.

05-GUIMARÃES, J.H.; PAPAVERO, N.; PRADO, A.P. AS miliasos na regiāo Neotropical (identificaçăo, biologia, bibliografia). Rov. bras. Zool., Săo Paulo, v.1, p.239 420, 1983.

O6-GUIMARĀES, L.M.; ARAÚJO, T.L.; GOMES, C.E.S. Sobre a presença do Gasterophilus Intestinalis (De Geer, 1776) om eqüinos P.S.C. no estado de São Paulo. Rev. Fac. Med. Vet, Ş̧o Paulo, v.5, p. 189-93, 1954.

07-IHERING, R. Vários casos de Oestrus - Gasterophilus no Brasil. Rev. Soc. Paul. Med. Vet, v.1, p.30-5, 1930.
O8-OLIVEIRA, C.M.; RASSIER, D.S.; LGNON, G.B. Gasterofilose equina no Rio Grande do Sul (Brasil). Observaçoes. Rev. Med. vot., Såo Paulo, v.8, p.61-6. 1972.

O9PANDEY, V.S.; OUHEШI, H.; ELKHALFANE, A. Observations on the epizootiology of Gasterophilus Intestinalle and G. nacalis in horse in Marocco. Vet Parasittol., v.7, p.347-56, 1980.

10-ROCHA, U.F. Observaçōes sobre gasterofilose om equideos da regiảo de Araçatuba, Estado de Sảo Paulo, Brasil. Rev. Fac. Med. Vet., Såo Paulo, v.5, p.17-25, 1954.

11-WEUS, R.W.; KNIPUNG, E.F. A report of some recent studies on species of Gasterophllus occurring in horses in the United States. Lowa St. Coll. J. Scl., v.12, p.110-28, 1938.

12-ZUMPT, F. Mylas's in man and animals in the Old World: a textbook for phyalcians, veterintrians and zoologlate. London, Buttenworth, 1965.

Recobldo para publicaģo em 13/06/91 Aprovado para pubtleaçäo em 21/05/82

TABELA 1 - Freqüência de gasterofilose em eqüldeos de 9 estados do Brasil, abatidos em Araguari, MG, no período de 14 de maio de 1987 a 10 de maio de 1988.

\begin{tabular}{lrrr}
\hline ESTADOS & $\begin{array}{c}\text { ANIMAIS } \\
\text { ABATIDOS }\end{array}$ & $\begin{array}{c}\text { ANIMAS } \\
\text { POSITNOS }\end{array}$ & $\begin{array}{c}\text { FREQüÊNCLA } \\
(\%)\end{array}$ \\
\hline Mato Grosso do Sul & 63 & 54 & 85,71 \\
Sảo Paulo & 1.767 & 1.342 & 75,95 \\
Paraná & 634 & 416 & 65,61 \\
Goiás & 3.398 & 1.496 & 44,02 \\
Mato Grosso & 69 & 29 & 42,03 \\
Minas Gerais & 7.999 & 1.122 & 14,03 \\
Pará & 12 & - & 8,33 \\
Espírito Santo & 196 & - & - \\
Pio de Jantiro & 24 & 4.460 & - \\
\hline TOTAL & 14.162 & & 31,49
\end{tabular}

